\title{
São Luís, a Manchester do Norte: a cidade (re)significada pelos discursos do patrimônio
}

\author{
St. Louis, North Manchester: the resignification of the city by \\ heritage discourses
}

\author{
Conceição Belfort CARVALHO \\ Universidade Federal do Maranhão (UFMA) \\ Kláutenys Guedes CUTRIM \\ Universidade Federal do Maranhão (UFMA)
}

\begin{abstract}
RESUMO: Considerando que o discurso, enquanto prática social historicamente determinada, constitui sujeitos e objetos (FOUCAULT, 1986), apresentamos uma análise de diversas práticas discursivas que constroem sentidos ao objeto patrimônio, buscando a emergência de acontecimentos que as fabricaram e produziram a cidade de São Luís como Athenas Brasileira, Manchester do Norte e, atualmente, como São Luís da diversidade. Em cada momento da irrupção do discurso de patrimônio este se materializa em textos e suportes de diferentes naturezas: a imprensa ilustra práticas discursivas que constroem a identidade de Athenas Brasileira; leis, documentos oficiais registram o epíteto Manchester do Norte e destacam uma simultaneidade de identidades, e a São Luís da diversidade nos mais diversos tipos de mídia que invadem o cotidiano (outdoors, folders). O conceito de patrimônio cultural, à luz da pósmodernidade, vai ganhando contornos que alcançam dimensões mais amplas, materializando-se no imaterial, em mecanismos de preservação, que envolvem a cultura e a memória.
\end{abstract}

PALAVRAS-CHAVE: Patrimônio, discurso, identidades.

\begin{abstract}
Whereas the discourse as a social practice historically determined, constitutes subjects and objects (Foucault, 1986) is an analysis of different discursive practices that make meaning to heritage object, seeking emergency events that manufactured and produced the city of St. Louis as Brazilian Athens, North Manchester and currently as St. Louis of diversity. In every moment of this outburst of heritage discourse is embodied in texts and media of different natures: the press illustrates discursive practices that build the identity of Brazilian Athens; laws, official documents record the North Manchester epithet and highlight an identity of simultaneity, and the St. Louis of diversity in various types of media that invade the everyday (billboards, folders). The concept of cultural heritage in the light of postmodernity, is gaining contours that reach broader dimensions, materializing itself in the imaterial, in preservation mechanisms that involve the culture and the memory.
\end{abstract}

KEYWORDS: Heritage, discourse, identities.

\section{Introdução}

A construção discursiva em torno do patrimônio cultural vai sendo edificada sob formas diversas. Para alguns, um dos elementos mais representativos estaria relacionado à cultura material; para outros, o patrimônio necessita ser visto de uma forma mais ampla, com destaque para aqueles que produzem a cultura, ou seja, os seres humanos.

O objetivo deste artigo é discutir o lugar das práticas discursivas na produção do sentido do objeto de discurso patrimônio e, por extensão, de identidades. Nosso 
propósito é olhar um objeto (o espaço de São Luís, transformado em patrimônio) à luz da genealogia das práticas discursivas que fizeram emergir, em diversos momentos históricos, as identidades que revestem um espaço e criam seus sentidos.

Para fundamentarmos nossas discussões, ancoramo-nos na genealogia de Michel Foucault e na ideia de discurso, visto enquanto uma prática social, historicamente determinada, que constitui os sujeitos e os objetos.

Um dos postulados de Foucault (1986) é o de que um objeto de discurso existe a partir de um complexo de relações de poder-saber, processos econômicos e sociais, formas de comportamentos, sistemas de normas, técnicas, tipos de classificação, modos de caracterização, que se estabelecem entre instituições. Tais relações constituem o discurso como prática discursiva que forma os objetos de que fala, os quais devem ser pensados de formas diferentes, em diferentes épocas e em diferentes instâncias.

O discurso constitui-se de um número limitado de enunciados, para os quais podemos definir um conjunto de condições de existência, por isso, ele "é, de parte a parte, histórico - fragmento de história, unidade e descontinuidade na própria história, que coloca o problema de seus próprios limites, de seus cortes, de suas transformações, dos modos específicos de sua temporalidade" (FOUCAULT, 1986, p. 135-136). O discurso é um complexo de enunciados, na medida em que se apoiem na mesma formação discursiva, completa Foucault.

O discurso é um conjunto de enunciados, estes, por sua vez, são performances verbais e não verbais em função enunciativa, daí decorre a ideia de "prática", prática discursiva. Foucault entende por prática discursiva um conjunto de regras anônimas, históricas, sempre determinadas no tempo e no espaço, que definiram, em uma dada época e para uma determinada área social, econômica, geográfica ou linguística, as condições de exercício da função enunciativa (FOUCAULT, 1986, p. 136).

A função enunciativa que organiza o discurso do patrimônio, em São Luís, surge num tempo determinado. Sua emergência e suas consequências estão ligadas a vários acontecimentos, dentre os quais destacamos o título de Patrimônio Cultural da Humanidade atribuído à capital maranhense, graças a toda uma demanda social que envolveu a participação de políticos locais.

Conforme destaca Foucault, o enunciado existe enquanto função enunciativa porque é produzido por um sujeito, em um lugar institucional, sendo determinado por regras sócio-históricas. (FOUCAULT, 1986), daí estarem sujeitos, enquanto discursos, a uma ordem, que preceitua aquilo que pode ser dito, aquilo que deve ser silenciado, submetido a regras de aparecimento e também suas condições de apropriação e de utilização, o que destaca desde sua existência a questão do poder, que é objeto de uma luta e de uma luta política.

O percurso temático dos enunciados que organizam o discurso do patrimônio no Brasil (e no mundo) se perfaz em um campo associativo com vários outros enunciados do discurso da preservação, da identidade nacional via memória coletiva e com diversos acontecimentos discursivos ligados a várias formações discursivas, dentre elas, em especial, as econômicas. (CARVALHO, 2009). Compreender essa trajetória que mantém o discurso do patrimônio faz parte de um esforço no sentido de compreender o campo associativo entre as formações discursivas dos enunciados específicos e sua dispersão nesse campo, já que todo enunciado relaciona-se a elementos de um campo antecedente, em relação aos quais ele se situa. Na descrição dos enunciados, a grande tarefa é a de definir as condições que deram a ele uma existência específica e nas quais ele se realizou. Esta existência faz aparecer um domínio de objetos que, com o enunciado, se relaciona. $\mathrm{O}$ enunciado passa a existir como um jogo de posições 
possíveis para um sujeito; como elemento em um campo de coexistência; como materialidade repetível (FOUCAULT, 1986).

Nosso estudo é permeado, também, pela discussão sobre identidade, memória e espaço. Nesse sentido, é inevitável que encontremos o sujeito, "seja enquanto objeto de saber, seja enquanto objeto de poder, seja enquanto objeto de construção identitária". (GREGOLIN, 2004, p. 58).

A fim de proceder às nossas análises, propomos um estudo da relação entre práticas discursivas e a produção histórica de sentidos. Nosso corpus constitui-se de um arquivo de discursos produzidos pelo governo do Estado do Maranhão, materializados em documentos como Códigos de Posturas, e em práticas discursivas não institucionalizadas, provenientes de entrevistas, em diversos suportes midiáticos (jornais, álbuns); práticas que situam sujeitos de diferentes campos do saber, tais como intelectuais (poetas) e todo um conjunto de discursos que possibilitam sua emergência a fim de constituir a cidade de São Luís como um espaço onde convergem várias identidades.

\section{Práticas discursivas e produção de sentidos do patrimônio}

Tendo como base a genealogia foucaultiana, focalizaremos o conceito de patrimônio que se edifica em São Luís a partir de uma descontinuidade entre quatro momentos históricos: a Athenas Brasileira; a Única capital brasileira fundada por franceses; a Manchester do Norte e a São Luís da diversidade.

Segundo Foucault, as coisas não preexistem às práticas discursivas, estas é que constituem e determinam os objetos. É, pois, a partir da reflexão sobre as transformações históricas do fazer e do dizer na sociedade ocidental - práticas discursivas que provocam fraturas, brechas e rearranjos nas configurações do saberpoder - que se edificam as questões em que propomos problematizar as práticas discursivas que provocaram rupturas e reorganizaram o discurso do patrimônio em São Luís em diferentes épocas.

Para tanto, é necessária uma discussão sobre a análise arquegenealógica do discurso, que não obedece às mesmas leis de verificação que regem a História Tradicional. Sob influência das leituras de Nietzsche, Foucault (2000) propõe uma história genealógica, que problematiza o passado, com o propósito de desvelar suas camadas arqueológicas, voltando-se para uma aguda crítica do presente. A genealogia se opõe ao método histórico tradicional, na medida em que seu objetivo é "assinalar a singularidade dos acontecimentos, fora de toda finalidade monótona" (FOUCAULT, 2007, p. 15). Para ela, inexistem essências fixas, leis subjacentes, finalidades metafísicas.

A história se fundamenta na continuidade, no progresso e seriedade. A genealogia trilha por um caminho oposto, o das descontinuidades, recorrências e jogo. Ela transita no espaço da superfície dos acontecimentos, nos mínimos detalhes, nas menores mudanças e nos contornos sutis: observada a correta distância, há uma profunda visibilidade nas coisas.

O discurso, para Foucault (1986), é constituído de um número limitado de enunciados para os quais podemos definir um conjunto de condições de existência. $\mathrm{O}$ enunciado é entendido como 
um acontecimento estranho, por certo: inicialmente porque está ligado de um lado a um gesto de escrita ou a articulação de uma palavra, mas, por outro lado, abre para si mesmo uma existência remanescente no campo de uma memória, ou na materialidade dos manuscritos, dos livros e de qualquer forma de registro; em seguida, porque é único como todo acontecimento, mas está aberto à repetição, à transformação, à reativação; finalmente, porque está ligado não apenas a situações que o provocam, e a conseqüências por ele ocasionadas, mas ao mesmo tempo, e segundo uma modalidade inteiramente diferente, a enunciados que o precedem e o seguem (FOUCAULT, 1986, p. 32).

Todo enunciado é uma função que cruza um domínio de estruturas e unidades possíveis e que faz com que tais unidades apareçam com diferentes materialidades no tempo e no espaço (FOUCAULT, 1986).

$\mathrm{Na}$ análise arqueológica, a organização de um conjunto de enunciados só pode ser realizada se considerarmos o seu pertencimento a uma certa formação discursiva: um conjunto de relações que regem o funcionamento do discurso, que determina o que pode e o que deve ser dito, em uma dada época, por determinados sujeitos. Toda vez que se "descrever entre um certo número de enunciados, um sistema de dispersão, e no caso em que entre os objetos se puder definir uma regularidade (uma ordem, correlações, posições e funcionamentos, transformações)", Foucault (1986, p. 43) afirma que estamos diante de uma formação discursiva.

Para uma análise arquegenealógica do conceito de "patrimônio" é preciso observar um conjunto de elementos formados de maneira regular por uma prática discursiva. Uma prática discursiva é uma espécie de saber e um saber

é aquilo de que podemos falar em uma prática discursiva que se encontra assim especificada: o domínio constituído pelos diferentes objetos que irão adquirir ou não um status científico; um saber é, também, o espaço em que o sujeito pode tomar posição para falar dos objetos de que se ocupa em seu discurso; um saber é também o campo de coordenação e de subordinação em que os conceitos aparecem, se definem, se aplicam e se transformam; finalmente, um saber se define por possibilidades de utilização e de apropriação oferecidas pelo discurso. (FOUCAULT, 1986, p.206-207)

$\mathrm{Na}$ esteira de Foucault (1986), podemos afirmar que haveria, no domínio do objeto, um disciplinamento na genealogia do conceito de patrimônio, uma espécie de normalização, de organização interna desse saber [como uma disciplina] tendo, em seu campo próprio, formas de homogeneização dos conteúdos, formas de hierarquização e, enfim, uma organização interna de centralização do conceito de patrimônio. (CARVALHO, 2009). Esse disciplinamento se manifesta em modos de objetivação: Códigos de Postura, que revelam práticas discursivas institucionalizadas, por um lado e, por outro, práticas discursivas não institucionalizadas, provenientes do campo literário, de entrevistas, numa variedade de suportes midiáticos (jornais, folderes, outdoors, álbuns). Explicar um objeto consiste em mostrar de que contexto histórico ele depende, pois as coisas só existem por relação; tudo é histórico, tudo depende de tudo (e não unicamente das relações de produção) (FOUCAULT, 1995). 
No domínio dos sujeitos, destacam-se o sujeito oficial na figura do poder público, o(s) sujeito(s) intelectual(is) - escritores, poetas. No domínio das possibilidades de usos, são tecidos discursos patrimoniais em defesa da preservação da memória. No domínio dos conceitos e das categorias, destaca-se uma associação ao termo patrimônio, o patrimônio histórico (material e imaterial).

Concebidas como objetos privilegiados na estruturação da análise arqueológica, as práticas discursivas constituem um conjunto preciso de procedimentos metodológicos, configurando-se como a mola propulsora do trabalho histórico-crítico da arqueologia.

Os discursos que edificaram a genealogia de "patrimônio" e a preservação da memória cultural foram produzidos em diferentes momentos históricos. O século XVIII, caracterizado pelo pensamento iluminista, tem particular destaque, por ter abraçado a ideia do progresso e por ter vislumbrado a ruptura com a história e a tradição. $\mathrm{O}$ Iluminismo caracterizou-se, dentre outras coisas, por uma incessante busca pelo progresso (BERMAN, 2007) que, por sua vez, produziu um sentimento de desenvolvimento e de felicidade, e a confiança de que a civilização humana alcançaria a perfeição e se distanciaria da barbárie.

A partir dessa concepção de progresso, é possível vislumbrar a temática do patrimônio, tendo em vista que este abrange questões relacionadas a temas como o da identidade. A consciência da perenidade e mudança, que permeia a vida humana, levará o homem a eleger símbolos que delimitem os traços de sua identidade, numa tentativa de legitimar a memória de fatos marcantes. Esse movimento vai promover escolhas do que deve ser eleito como patrimônio e se faz em meio a um jogo de representações de elementos associados à elite. Os prédios tombados são os de famílias ricas, igrejas (bens religiosos), fortes (representativos do poder militar) etc.

Dentre os vários elementos que configuram uma cidade como patrimônio destaca-se um imaginário social, ou seja, "um sistema de idéias e imagens de representação coletiva que os homens, em todas as épocas, construíram para si, dando sentido ao mundo" (PESAVENTO, 2004, p.43).

No Brasil, várias cidades receberam o título de Patrimônio Cultural da Humanidade. A cidade de São Luís foi elevada a essa condição por meio do agenciamento de diferentes discursos.

Os acontecimentos que produzem tais discursos são determinados pela história e se apresentam em forma de memórias, fatos, narrativas, como os que promovem em São Luís o mito da Athenas brasileira. O epíteto "Atenas Brasileira" era atribuído a uma cidade cujos intelectuais desenvolviam atividades culturais e literárias.

Em São Luís, houve a criação do Grupo Maranhense, composto de intelectuais escritores, dentre os quais destacam-se nomes como Antonio Gonçalves Dias, Joaquim de Sousa Andrade, mais conhecido por Sousândrade. Esse grupo dá visibilidade à capital maranhense em nível nacional, provocando uma mudança nos costumes locais. O gosto pelas letras desperta o gosto pela arte. As famílias de mais posse reservam em suas casas espaços para saraus, apresentações teatrais, operetas. Há um despertar para a arte teatral.

Mas mudanças no âmbito político - como a proclamação da República, a abolição da escravatura - e econômico, como a queda da agroexportação produziram consequências e transformações no panorama maranhense. A historiografia registra um ciclo decadentista cultural entre 1894 e 1932.

Essas transformações provocaram nos maranhenses uma letargia. Era preciso reagir diante de tal situação. Era o momento de propor mudanças no sentido de resgatar o passado. A Segunda Geração, que atuou entre 1870 e 1890, para manter a tradição de 
Atenas Brasileira, promoveu uma formação discursiva, com base na valorização da fundação francesa de São Luís. O discurso de fundação sugere um retorno às origens e também um salto para o futuro, pois a França simbolizava os novos tempos.

A capital maranhense vai se adequando aos novos ares do progresso. Essa adequação se dá, por um lado, pelo discurso de valorização da origem francesa e, por outro, pela racionalização do espaço físico a partir das ideias de higienização, que implicam em demolição do patrimônio material. Vários casarões de origem colonial são demolidos para dar lugar a largas avenidas.

O processo identitário dá-se sob condições em que uma nova figuração não elimina a anterior. Isso é o que observamos quando, em São Luís, inicia-se a destruição do patrimônio material, considerado pertencente a um passado colonial, tido como superado, e pela construção do novo, reflexo da industrialização, e que vai promover São Luís como a Manchester do Norte. Edificada pelo ideal de modernização, a partir do advento da Revolução Industrial, tal referência é feita à cidade de Manchester, Inglaterra, que se destacou no início da Revolução Industrial. Essa transformação em São Luís produziria um conjunto de iniciativas e elementos que alterariam o retrato histórico, construído no decorrer do século anterior.

Assim, são eleitos, pela elite, alguns símbolos de tecnologia, civilização e progresso, no sentido de adequar à cidade ao ideal de desenvolvimento: o parque industrial têxtil, as Exposições, os Códigos de Postura, o discurso médico sanitarista. Esses símbolos instituem novas formas de disciplinamento dos corpos, por meio de uma nova configuração geográfica, em nome de um novo processo civilizatório.

Em seu discurso de abertura da Exposição de 1912, o presidente da Sociedade Festa Popular do Trabalho, Domingos Perdigão, destaca a fundação francesa de São Luís, como um acontecimento que aproximava a capital do Maranhão dos modelos do liberalismo político francês e da organização espacial de Paris:

\footnotetext{
Trezentos annos são passados que a gloriosa França fundou esta formosa cidade, em que habitamos. [...] um povo forte, acostumado a andar na vanguarda de todos os idéaes da humanidade, e foi pôr isso que aqui veio, e tudo soube conseguir dos valentes possuidores da terra [os índios] e, como para dar-lhes um exemplo da civilização européa, fundou a cidade de São Luiz, aqui, justamente no lugar onde existe a gloriosa Athenas Brasileira, formosa Capital do Estado do Maranhão. [...] E se elles conseguiram mostrar [...] como se principiava a edificar uma cidade, nós queremos ter a vaidade de continuar a desbravar o caminho do progresso, que foi iniciado pelos fundadores da sociedade promotora da exposição que hoje se inaugura [...] (ÁLBUM..., 1913, p. 6).
}

Há nesse discurso um retorno à fundação francesa no sentido de fortalecer o ideário progressista da elite comercial, que está, assim como os europeus, na "vanguarda dos ideais da humanidade" e que pretendem dar continuidade ao progresso aqui iniciado. Destaca-se também o retorno ao discurso da Atenas Brasileira, que procura na Grécia uma origem edificante.

As sociedades disciplinares, conforme destaca Foucault (2002), conduzem uma forma de poder, que tenta garantir a ordenação das multiplicidades humanas. Essa forma de poder se dá por meio de uma "ortopedia social", que produz corpos dóceis e que torna o exercício do poder economicamente o menos custoso possível, prolongando os 
efeitos do poder social e atrelando o crescimento econômico do poder ao rendimento dos aparelhos pelos quais se exerce, não importando se eles são pedagógicos, militares, industriais, médicos, desenvolvendo tanto a docilidade quanto a utilidade de todos os elementos do sistema. Um desses aparelhos são os Códigos de Postura, que se articulam por meio da vigilância hierárquica sobre os indivíduos, a partir de uma organização e ocupação do espaço físico.

Os Códigos de Postura (CP) se inscreviam na ordem do discurso do processo civilizatório, lançado pelo liberalismo francês e adotado em São Luís numa época de efervescência industrial.

Na Província do Maranhão, uma Assembleia Legislativa Provincial inicia seus trabalhos em 1835, com a competência de analisar, aprovar, revogar ou modificar as posturas propostas pela Câmara de cada município (CARVALHO, 2005).

Instrumentos normativos que fundavam parâmetros gerais para o convívio em sociedade, os CP traduzem práticas discursivas institucionalizadas que estabelecem normas nas formas de edificação e organização do espaço e também do corpo, no sentido de instituírem um padrão nos procedimentos de ocupação do espaço físico e uma homogeneização do corpo (do individual para o coletivo), numa tentativa de conter a diversidade, de transformar as multidões em "multiplicidades organizadas":

As ruas que dora em diante se abrirem nesta cidade terão a largura de pelo menos vinte metros de casa a casa, reservando-se para as testadas, de cada lado dois metros. Estas ruas e testadas serão sempre em direção recta (Coleções de Leis e Resoluções Municipais de 18921903, Capítulo XXIV, Art. 202).

O poder exerce-se em todas as relações sociais e é microfisicamente difundido em diversas formas (FOUCAULT, 1979). As tecnologias de poder praticadas pelos Códigos de Posturas apresentam as normas de funcionamento da cidade de São Luís por meio de estruturas disciplinadoras, que regulavam o espaço físico (a largura das ruas) e, por extensão, os corpos em um desejo de acomodar-se aos novos padrões de modernidade exigidos pelo processo civilizatório. "Crenças e tradições se dissipavam, e possibilitavam um novo estilo de vida, que se organizava à medida que o espaço físico se alterava e se mecanizava". (CASTRO, 2014, p.)

Esses acontecimentos discursivos vão produzindo sentidos na/para a cidade. E o que constitui um acontecimento discursivo? Ele é qualquer coisa que se solta do "murmúrio anônimo". É tarefa da análise do discurso descrevê-lo. O acontecimento discursivo pressupõe a anterioridade de um "há linguagem" (FOUCAULT, 1986, p.146). Há o "murmúrio anônimo" e, de repente, dá-se um acontecimento, qualquer coisa que é dita. Sabemos que alguém disse, mas não sabemos quem. Não há como precisar, pois o murmúrio é anterior.

Conforme podemos observar, as mudanças no conceito de patrimônio foram acompanhadas, e também foram decorrentes, de vários acontecimentos e transformações históricas, sociais, políticas, que reatualizam uma memória por meio da seleção de símbolos representativos de sua identidade: a cidade que é Atenas brasileira, Manchester do Norte, a cidade de fundação francesa. Nesse movimento de lembrar e relembrar, interessa a memória de fatos importantes que marcaram sua história (CUTRIM, 2012). As mudanças fizeram São Luís adentrar na pós-modernidade como Patrimônio Cultural da Humanidade. 
E como Patrimônio da Humanidade, o discurso em torno de São Luís se constrói sempre no sentido de exaltar suas qualidades, atores, espaços colocando a sociedade em uma relação de forças, da qual a mesma é objeto e age de maneira subjetiva nas suas participações, haja vista que se torna um elemento conduzido nas práticas discursivas e também cotidianas (CARVALHO, 2009).

As formações discursivas que promovem a cidade como patrimônio da humanidade, presentes em jornais, são compostas por memória, identidade e sociedade. Nessa trama, entrelaçam-se também a celebração das características do lugar de pertencimento.

No Caderno "São Luís - Patrimônio da Humanidade", de 19 de dezembro de 1997, do Jornal O Estado do Maranhão, José Sarney no texto São Luís, poesia e cravo destaca a história da cidade de forma poética, apagando os problemas e construindo a imagem de uma cidade que resguarda uma forma majestosa em um lugar ideal:

Deus quando fez o mundo, deixou para fazer o Maranhão no último dia, um lugar para ele descansar. [...] Deus aqui é pobre, não tem ouro nem prata, tem pedra e cal, com essas matérias fez ruas tão belas, espaços tão majestosos feitos de luz e de estrelas. [...] Aqui não se erguem estátuas a heróis e soldados, políticos e administradores. Somente a poetas e escritores (O ESTADO DO MARANHÃO, [19 dez.] 1997).

Em outro trecho do mesmo caderno há uma expressão de orgulho, ostentação das grandes riquezas e dos grandes feitos. A identidade local desempenha uma dupla função: manter-se e propagar-se, simultaneamente, em tempos e espaços distintos:

Agora, São Luís é da humanidade [...] São Luís é assim: o belo e o trágico estampados nas cimalhas, com suas mísulas entalhadas, capitéis de volutas, beirais duplos em telhas esmaltadas. Conheçam a cidade em que a lenda e a realidade andam de braços dados. Em cada esquina um sobradão reluzindo azulejos, a lembrar do tempo em que a arquitetura era arte.

Há, nesse sentido, uma rede discursiva que abrange as práticas relacionadas ao Patrimônio Cultural. No funcionamento dessa rede existe um processo que seleciona fatos, glorifica atos e promove atores sociais capazes de manobrar uma sociedade em torno de um vínculo identitário.

São Luís, no desejo de se inserir em novos padrões, vê destacarem-se novos ícones identitários. A capital acompanha a emergência de identidades que brotam da cultura popular, da periferia, as quais ganham grandezas simbólicas importantes em uma lógica capitalista.

A simultaneidade de diferentes identidades, em São Luís, sugere a reunião de todos os gostos, tempos, formas, crenças, comportamentos, numa atitude típica do homem pós-moderno. Nessa conexão de identidades tem destaque a "São Luís da diversidade", que insurge no limiar do século XXI. Tal identidade é consagrada em 2009, ano em que São Luís é eleita a Capital Brasileira da Cultura, título que visa à valorização do patrimônio artístico e cultural.

O funcionamento desse título dá-se pela apropriação dos órgãos do poder que passam a mobilizar essa memória, por meio de vários mecanismos enunciativos na cidade. Em inúmeros ambientes discursivos (outdoors, folders etc.), em diferentes momentos, essa identidade emergente (São Luís - capital brasileira da cultura) foi 
projetada num insistente movimento de enunciação pelo espaço da cidade. Um dos elementos da cultura popular que fizeram/fazem funcionar essa identidade é a festa do bumba-meu-boi.

Conforme destaca Carvalho (2014, p. 56),

As festas proporcionam ao sujeito, em curto espaço de tempo, experiências e identidades nunca antes vivenciadas. Elas podem ser consideradas lugares-tempo onde as identidades se movem, fogem e reaparecem para celebrar a dispersão dos sujeitos.

A culminância dessa festa é o mês de junho. O poder público - prefeitura e governo do Estado - divulgam o São João, como é mais conhecida a festa, em vários suportes tais como outdoors, folders, e trazem em suas estampas, índias (dançarinas) do bumba-meu-boi; coreira (brincante do tambor de crioula, outra festa muito popular no Estado); fofões (personagem do carnaval); a imagem de um boizinho com os seguintes enunciados: "São João 2009. De 31 de maio a 30 de junho. Praça Maria Aragão", "A capital brasileira da cultura festeja a diversidade"; e o slogan da prefeitura em 2009: "Prefeitura de São Luís - cidade de todos".

Esses enunciados, juntamente com o motivo do festejo, constituem um trabalho de subjetividade, na medida em que demarcam a data da festa e o lugar onde ela vai ocorrer: a praça. Espaço público, a praça "funciona como uma tecnologia de administração da vida social, um complexo dispositivo histórico", por meio de "uma prática cotidiana, que se configura em uma estratégia de poder, dotada de uma tecnologia voltada para o bem-estar social e biológico da população" (CARVALHO, 2009, p. 121).

Espaço onde se cultua a festa, São Luís é constantemente lembrada no slogan da prefeitura como uma "cidade de todos"; um lugar onde se festeja a diversidade e onde o patrimônio é representado em figuras da cultura popular que reúnem personagens do dia a dia. A ideia de patrimônio já não é mais associada a bens representativos de uma elite econômica; tornou-se, na modernidade, elemento da cultura popular.

As relações sociais e espaciais se modificam no andamento do tempo, mas isso não se faz sem conflitos, contradições e resistências. Cada local tem sua formação particular, sua cultura, valores e costumes e, desse modo, o espaço é produzido segundo essas relações mais amplas, em um processo articulado à produção geral da sociedade.

\section{Considerações Finais}

Em São Luís, as discussões em torno da genealogia do conceito de patrimônio promovem várias práticas discursivas. Constrói-se um imaginário social em torno de várias singularidades que se edifica em um sistema de ideias e imagens erigido pela elite dominante. Vários acontecimentos derivados dessa construção fazem irromper o conceito de patrimônio.

O discurso configura-se como elemento de base dessa genealogia, construindo o mito da Atenas Brasileira, que reflete uma visão imaterial de patrimônio, no campo literário, na figura de intelectuais maranhenses e que tenta aproximar os costumes ludovicenses de uma cultura erudita.

Outras práticas discursivas constroem uma nova identidade, ligada à industrialização de São Luís, e vai produzir o epíteto Manchester do Norte, ligado a diversos saberes, como o de uma nova política de ocupação do espaço público, e que promove também uma nova forma de organização dos corpos. Nesse momento, tenta-se negar a arquitetura e os costumes de base colonial. Nasce uma nova singularidade: a de 
única capital fundada por franceses, que funda um retorno ao passado e, ao mesmo tempo, aponta para o progresso, representado pela França.

As transformações da pós-modernidade produzem uma nova construção identitária e aponta para um novo conceito de patrimônio (material e imaterial) e para a constituição da São Luís da diversidade.

Conforme pudemos observar, cada uma dessas identidades emerge em um momento histórico e circula em textos de diferentes naturezas, materialidades e suportes. Assim, a Atenas Brasileira materializa-se no discurso literário e em jornais, a Manchester do Norte materializa-se em discursos de base sanitarista em Códigos de Postura, e a São Luís da diversidade nos mais diversos tipos de mídia que invadem o cotidiano (outdoors, folders).

\section{Referências}

ÁLBUM Comemorativo do $3^{\circ}$ Centenário da Fundação da Cidade de São Luís, Capital do Estado do Maranhão. São Luís: Typografia Teixeira, 1913.

BERMAN, M. Tudo que é sólido desmancha no ar: a aventura da modernidade. 2. ed. São Paulo: Companhia das Letras, 2007.

CARVALHO, Conceição de Maria Belfort. O discurso ressignificando o espaço da cidade. In: CRUZ, M. da S.; CUTRIM, I. G.; CABRAL, L. R. (Orgs.). Discursos, sujeitos e sentidos: perspectivas identitárias. Curitiba: Editora CRV, 2014.

A genealogia do patrimônio em São Luís: da Athenas à capital da diversidade. Tese (Doutorado em Linguística e Língua Portuguesa) - Programa de PósGraduação em Linguística e Língua Portuguesa, Universidade Estadual Paulista Júlio de Mesquita Filho - Faculdade de Ciências e Letras, Araraquara, 2009.

CARVAlHO, H. F. Urbanização em São Luís: entre o institucional e o repressivo. Dissertação (Mestrado em Ciências Sociais) - Programa de Pós-Graduação em Ciências Sociais, Universidade Federal do Maranhão, São Luís, 2005.

CASTRO, Andreia A. M. de. As cidades e os seus mistérios - formas importadas, ajustes locais. Revista Línguas \& Letras. Unioeste, Vol. 15, No 29 - Segundo Semestre de 2014.

CUTRIM, Ilza Galvão. Na mira da mídia: acontecimento discursivo e produção de identidades em torno da fundação da cidade de São Luís. VIII ENECULT ENCONTRO DE ESTUDOS MULTIDISCIPLINARES EM CULTURA. Salvador, 2012. Disponível em file:///C:/Users/User/Downloads/40541\%20(1).pdf <Acesso em 12 de abril de 2015>

FOUCAULT, M. O nascimento da medicina social. In: Microfísica do poder. Organização e tradução de Roberto Machado. 23. ed. Rio de Janeiro: Graal, 2007.

Nietzsche, a Genealogia e a História. In: MOTTA, M.B. (Org.). Michel Foucault. Ditos e Escritos II. Rio de Janeiro: Forense Universitária, 2000. p. 260-281.

As palavras e as coisas. São Paulo: Martins Fontes, 1995.

Arqueologia do saber. Rio de Janeiro: Forense Universitária, 1986.

Graal, 1979.

Microfísica do poder. Trad. Roberto Machado. Rio de Janeiro: edições 
GREGOLIN, Maria do Rosário. Análise do discurso e mídia: a (re)produção de identidades. In Comunicação, mídia e consumo. São Paulo, vol. 4 n. 11, p. 11 - 25 nov. 2007.

Foucault e Pêcheux na construção da análise do discurso: diálogos e duelos. São Carlos, SP: Claraluz, 2004.

O ESTADO DO MARANHÃO. São Luís, 19 dez. 1997. Caderno "São Luís Patrimônio da Humanidade".

PESAVENTO, S. J. História e História Cultural. Belo Horizonte: Autêntica, 2004.

PORTO, A. (Org.). Publicações da Câmara Municipal de São Luís: Coleção de Leis e Resoluções Municipais (1892-1903). São Luís: Tipografia do Diário do Maranhão, 1910. p. 11-33. 